\title{
Off-label PuraStat use for the treatment of acute intrahepatic biliary duct bleeding
}

PuraStat (3-D Matrix Europe SAS, France) is a novel self-assembling peptide hemostatic hydrogel that currently is used in surgery and in digestive endoscopy, where it has been shown to be effective and safe as a rescue therapy for both upper and lower acute gastrointestinal bleeding [1] and as prophylactic treatment after wide endoscopic mucosal resections and submucosal dissections [2]. We performed cholangioscopy (Spyglass DSII, US Boston Scientific) in a 78-yearold man with cholangitis and massive hepatolithiasis. After electrohydraulic lithotripsy (Northgate Autolith IEHL) and stone fragment retrieval, fresh blood started oozing from one of the intrahepatic biliary ducts, inside a biliary cystic dilatation at the IV hepatic segment.

Because the bleeding site was inaccessible using endoscopic hemostatic devices, a feasible option was off-label application of hemostatic hydrogel. The hemostatic hydrogel catheter is compatible with a $2.8-\mathrm{mm}$ diameter working channel, whereas the cholangioscope working channel has a $1.2-\mathrm{mm}$ diameter. Therefore, we transferred the hemostat-

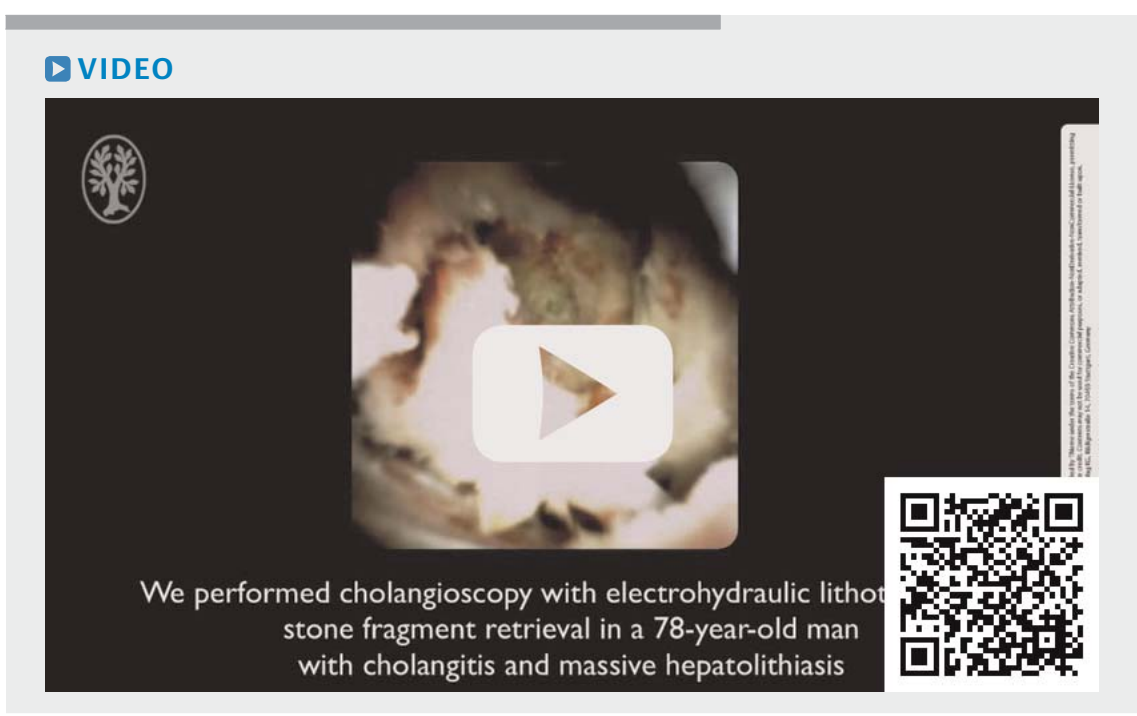

Video 1 Full-length video showing the procedure. ic hydrogel from the $1-\mathrm{mL}$ prefilled syringe to a $10-\mathrm{ml}$ Luer-lock syringe. After suctioning out the previously instilled $0.9 \%$ saline to avoid dissolving the hemostatic agent, we pushed the hemostatic hydrogel through the working channel, aiding its progression with an air-filled syringe ( $>$ Video $\mathbf{1}$ ). The hemostatic hydrogel effectively covered the bleeding point, resulting in complete hemostasis.

Both cholangioscopy and hemostatic hydrogel application within biliary ducts would seem situations of increased risk for subsequent cholangitis; however, the formulation of the hemostatic hydrogel is water-based, unlike other hemostatic agents available, which are powders. Moreover, as recommended, we administered an intravenous antibiotic before the procedure and we monitored the patient on the ward. No further cholangitis or bleeding episodes occurred, and the patient was discharged home 3 days later.

\section{Conclusions}

In conclusion, off-label hemostatic hydrogel application may be useful for obtaining hemostasis in the biliary tract, where procedures or devices such as injection of diluted epinephrine and clip deployment are technically not applicable.

\section{Competing interests}

The authors declare that they have no conflict of interest.

The authors

Paola Soriani, Paolo Biancheri, Simona Deiana, Laura Ottaviani, Mauro Manno Gastroenterology and Digestive Endoscopy Unit, Azienda USL Modena, Carpi Hospital, Italy

\section{Corresponding author}

\section{Dr. Paola Soriani}

Azienda USL Modena, Gastroenterology and Digestive Endoscopy Unit, Via Guido Molinari 2, 41012 Carpi (MO), Italy

Fax: +059659500

paola.soriani@gmail.com

\section{References}

[1] De Nucci G, Reati R, Arena I et al. Efficacy of a novel self-assembling peptide hemostatic gel as rescue therapy for refractory acute gastrointestinal bleeding. Endoscopy 2020; 52: 773-779

[2] Subramaniam S, Kandiah K, Thayalasekaran $S$ et al. Haemostasis and prevention of bleeding related to ER: The role of a novel self-assembling peptide. United European Gastroenterol J 2019; 7: 155-162 
Bibliography

Endosc Int Open 2021; 09: E1926-E1927

DOI 10.1055/a-1608-0931

ISSN 2364-3722

(C) 2021. The Author(s).

This is an open access article published by Thieme under the terms of the Creative Commons Attribution-NonDerivativeNonCommercial License, permitting copying and reproduction so long as the original work is given appropriate credit. Contents may not be used for commercial purposes, or adapted, remixed, transformed or built upon. (https:// creativecommons.org/licenses/by-nc-nd/4.0/)

Georg Thieme Verlag KG, Rüdigerstraße 14,

70469 Stuttgart, Germany

$($ 이 $\$ \odot$ 